\title{
The Zombie Aesthetics and the Post-Apocalyptic Franchise
}

\author{
By Kevin Stewart \\ Spring 2007 Issue of KINEMA
}

\section{THE ZOMBIE AESTHETICS AND THE POST-APOCALYPTIC FRANCHISE}

ON MARCH $22^{\text {nd }} 1996$, Japanese video game company Capcom Inc. released Biohazard, the first of their new immersive zombie survival-horror role playing games (RPGs) for the Sony PlayStation. Released in the West as Resident Evil, George A. Romero's model of the animated cadaver and Lucio Fulci's command of the atmospheric combined to provide the main inspiration for the game's visual and narrative aesthetic (Poole, 79): a complete and immersive reworking of the zombie genre by Tokyo based video game producer Shinji Mikami. Although not the first video game franchise to attain cult recognition or make a successful transfer to the big screen - Lara Croft and the Tomb Raider franchise come to mind - a determination, "to repackage the zombie as a mainstream monster and an icon of cool" (Russell, 171) clearly paid off:

The Resident Evil games had succeeded in taking zombies out of the margins and into the mainstream. Capcom's $\$ 600$ million smash hit video game franchise - more profitable than most zombie releases put together - achieved something that nothing else had ever managed: it made Romero's zombies into A-list stars. The living dead might never have had the luck to headline a hugely profitable blockbuster movie, but in the increasingly convergent world of video games they were enjoying the equivalent kind of success. (Ibid, 171)

Mikami not only successfully remediated the established generic aesthetic of Romero's atmospheric décor; he redefined it. He introduced a substantial element of generic hybridity into the mix, by retaining the characteristics of the gothic horror, of doom, death and decay, and fusing them almost seamlessly with the iconography of science-fiction. Consequently, graveyards, crypts, and mansions appeared juxtaposed against technologically burgeoning scientific laboratories, bio-engineered creatures, and impressive underground transportation systems. His refashioning of the genre's aesthetic composition marks a landmark stage in the development of the screen zombie (Poole, 16-19). The game immediately spawned two commercially successful block-busting screen adaptations, Resident Evil (2002), and Resident Evil: Apocalypse (2004), with a third film, Resident Evil: Extinction (2006/7) currently in production, and a fourth yet to be scripted. Both films were released on the back of series of episodic RPGs across a range of gaming platforms. Commenting on the first film's aesthetic, horror writer Robert Hood notes:

From the first entrance of the dead - shambling, distorted and snarlingly intent on taking a bite out of anything that moves - we know we're in Romero territory, and as the stories continue and the zombies amass, the film takes us on a roller coaster ride that manages to successfully fuse modern action-film aesthetics with Romeroesque imagery (Hood, 2002).

The "Resident Evil effect" (Russell, 171-174) has boosted zombie film production which has spiralled since the late 1990s. The zombie RPG has clearly had a significant role to play in the reversal of fortune enjoyed by the screen zombie. The evidence is undeniable. Wilson Yip's Bio Zombie (1998) directly refers to the RPG aesthetic, when, some three-quarters of the way through the film, the narrative suddenly stops. Then, in a highly stylized sequence of angularly framed canted shots that clearly emulate the RPG aesthetic, the strengths and weakness of each character are graphically displayed on screen, in much the same way as they would be if a game player were selecting his or her preferred avatar. However, the most compelling comment of all comes from Simon Pegg, co-writer and "Shaun" from Shaun of the Dead (2004) who asserts that "Resident Evil is directly responsible" (Ibid, 183) for the current cycle of generic popularity. Furthermore, in addition to establishing the survivor-horror RPG as a new and exciting sub-generic form, Resident Evil has inspired a selection of similarly successful action adventure RPG franchises (Poole, 118): Konami's supernaturally premised four game Silent Hill (Ibid, 78-79) series having recently premiered in cinemas across the globe, and Kronos Digital Entertainment's Fear Effect currently in the early stages of pre-production.

There are, in all probability, a range of factors that contributed to the phenomenal success of the Resident 
Evil franchise, but unfortunately most lie beyond the scope of this paper. However, Mikami's refashioning of the aesthetic has had a significant role to play in the revival of the zombie genre, and in particular, its newfound screen presence: a stage of aesthetic development that can be clearly traced from George A. Romero's Dawn of the Dead onward. When comparing the aesthetic composition of the film to that of the Resident Evil series, there is a clear and direct replication and refashioning of elements from the film's generic make-up, refashioned in this instance in auteurist terms as the composition of the screen-image where a mix of mise-en-scène, montage and sound is "crucial both for the way the film functions and for its effect on the audience" (Lothe, 8). It is this very refashioning of the generic aesthetic that underpins the success of Mikami's reworking and the genre's revived screen fortunes. Although both cinema and the video game have grown increasingly dependent on the exchange of aesthetic and narrative content, it has not been until quite recently that researchers such as King \& Krzywinska (2002), Wolf \& Perron (2003) and Buckingham et al. (2006) have begun to turn their attention to this quite dynamic and fascinating "merging of languages" (King \& Krzywinska, 1), a reciprocal process of remediated aesthetic expression between both media.

The term remediation can be defined in two distinct ways. Firstly as a process where "new media technologies improve upon or remedy prior technologies" (Bolter \& Grusin, 60); in film for instance, the transition from $16 \mathrm{~mm}$ film to video-cartridge to video-tape to DVD disc, or in ludological terms from board games to electronic games to video games. Secondly, as Bolter \& Grusin (2000) theorize "as the formal logic by which new media refashion prior media forms" (Ibid, 60); citing film as an example, shifting cultural values, changing ideologies, expectations, audience sophistication etc. Both forms of remediation are applicable here. In the first instance, the video game has provided a new mode of delivery for cinema by the incorporation of cinematic sequences within game narratives. In the second instance, the nature of the video game experience itself privileges the redefining of generic expectation and convention. In the case of Resident Evil, Mikami took elements from a specific generic aesthetic, that of Romero's. He then premised the construction of Resident Evil's world on this established aesthetic model. However, rather than just simply replicating Romero he redefined the aesthetic, reworking and refashioning, in a process of generic remediation that privileged transparent "liveness" and "presence" (King \& Krzywinska, 4): a process of immediacy "where the medium fully disappears from the consciousness and the experience of full immersion becomes possible" (Bolter \& Grusin, 21-22). However, following on from the success of the Resident Evil RPGs, the remediation process has now entered a significant stage of reversal. Cinema has acknowledged the success garnered by the refashioning of the generic aesthetic, and has been more than willing to reinvent the screen zombie by replicating and adapting the remedial benchmark set by Resident Evil; in effect, to remediate the remediated. An extract from an editorial published in 2002 in Cahiers du Cinéma stated the following:

Henceforth, the video game no longer needs to imitate the cinema to exist because it proposes hypotheses that cinema has never been able to formulate, as well as emotions of another nature. If video games have looked to the cinema in the past (their designers are also moviegoers), today they allow us to look at the cinema differently, to question it in its modes of functioning and its theoretical principles. Video games are not only a social phenomena, they are the essential crossroads in a redefinition of our relation to the narrative world in images, prolonging what Godard had formulated ("A film: between the active and the passive, between the actor and the spectator"), without knowing that the video game was going to seize this question, to reply to this demand, while leaving the cinema without reply. (Cahiers du cinéma, in Wolf \& Perron, 8)

It appears that cinema has indeed begun to respond, with the current cycle of zombie films testament to this fact. However, given the ludological nature of the video game experience, the Resident Evil aesthetic also demonstrates qualities that Bolter \& Grusin refer to as reflecting characteristics of the process of hypermediacy (Bolter \& Grusin, $31 \& 272$ ). Although the term is in opposition to the theory of transparent immediacy, it is still closely linked (King \& Krzywinska, 4). It refers to a "style of visual representation whose goal is to remind the viewer of the medium" (Bolter \& Grusin, 31 \& 272) and "emphasizes process or performance rather than the finished art object" (Mitchell, in Bolter \& Grusin, 31). In the case of the Resident Evil RPGs much of the interactive participation is interspersed with cinematic cut-scenes that both bind and propel the segmented narrative(s) within the numerous multi-levels of play. In this case the hypermediated "visual style" is cinema (King \& Krzywinska, 4). Furthermore, running through each of the RPGs, the player is invited to engage in challenges, refer to documents and files, to manage resources and 
so on. In these instances, the hypermediation takes the form of textual and graphic conventions borrowed from the print media.

Today, the sophistication, design and commerciality of the video game demands as much effort in pre- and post-production as does any block-busting movie (Poole, 10), but there are distinct differences between the two in terms of their defining apparatus of "interconnected technical, environmental, textual, psychological and social processes" (Morris, in King \& Krzywinska, 81). In the first instance, the cinema lends itself to spectacle. Audience engagement occurs through an emotional relationship with the screen, with no need for physical interaction. However, the video game demands that a physical interaction be established: "You play it" (Poole, 39) via a controller or keyboard interface. As Wolf \& Perron note:

The video game is unlike any media to come before it, being the first to combine real-time game play with a navigable, onscreen diegetic space; the first to feature avatars and player-controlled surrogates that could influence onscreen events; and the first to require hand to eye coordination skills (Wolf \& Perron, 11).

Furthermore, unlike two-dimensional flat screen games, the survival-horror RPG occupies three-dimensional space in much the same way as cinema (Burn \& Buckingham, in Buckingham et all, 28). Therefore, in order to evoke a similar participatory engagement with the text, not only must the video game be sufficiently appealing both aesthetically and interactively, but at a considerably greater immersive, intensive and personal level. RPG's demand that the player engage with the text as avatar, from a selection of characters, each with specific roles within the narrative (Poole, 40-41), completing tasks, solving puzzles, and so forth. Like most RPGs, the survival-horror has its own distinct mix of generic characteristics. Commenting on the Resident Evil, Russell notes:

Moving through each level, players are confronted by a range of atmospheric locations that use carefully chosen sound effects such as dripping water, breaking glass and the moans of off-screen zombies to heighten the tension. Much like a conventional horror movie, the game makes use of a creepy score interspersed with long sections of disturbing silence to help set up its scripted "shock" moments: zombies smashing through the windows of a deserted hallway as the player's avatar walks along it; a pack of living dead dogs that suddenly leap into the playing area from somewhere off-screen; a zombie unexpectedly lurching out of the shadows (Russell, 171).

As I have already mentioned, much of the aesthetic composition within the Resident Evil RPGs was borrowed directly from Romero, and in particular from his second film, Dawn of the Dead. One of the most identifiable aspects of Romero's mise-en-scène to successfully remediate from his film, later reworked within Mikami's Resident Evil RPGs, is that of décor: the design and arrangement of the location and the artefacts positioned within the framed setting. By applying a limited textual analysis focused purely on décor composition, one can clearly identify the process of remediation at work. This process can be charted as it travels from Dawn of the Dead into the earlier releases in the Resident Evil RPG series and through the later film adaptations, before, and most tellingly of all, returning to underpin Zack Snyder's significantly altered $\$ 28$ million remake of Dawn of the Dead in 2004.

Accordingly, in the remainder of this paper I will proceed to identify by example indisputable evidence of the remedial process in motion as it makes its journey across and through the aforementioned texts. In the first instance I will demonstrate the process as it moves from Romero's original film and into the Resident Evil RPG. Secondly, even though Snyder's film is considerably different from Romero's original, I will further demonstrate the process in reverse, as it transfers back to cinema to significantly feature in the aesthetic composition of Snyder's remake. Although there are numerous other examples of remedial refashioning throughout the texts, there are simply too many to detail in this paper. Therefore, I have selected a small but compelling choice of examples to present as indisputable evidence of a clear process of aesthetic remediation which, to begin with, refashion décor in terms of location and setting.

One of the first locations to undergo a significant degree of remediation - to then appear refashioned in the Resident Evil RPGs - are the police offices by the riverside who feature in Romero's second Dead outing. In the film, the "Police Dock" offices are the headquarters of a small unit housing police helicopters and boats. Entry is gained through a small locker room to the back of the main office. In a long shot (LS), Stephen 
(David Emge) enters from a door in the middle of the back wall. To his right stand two large lockers and to his left, running along the length of the wall, a few more. Running vertically along the left edge of the screen frame one can see a beige coloured wooden door frame, and to the right, some brown cardboard boxes stored on top of the lockers, with some posters fore-grounded in shadow. As I will now show, this arrangement of décor can also be identified, albeit refashioned, within Mikami's Resident Evil 2 RPG.

The police offices now form part of the much larger Raccoon City Police Department (RPD). This time, the game player's choice of avatar, Leon Kennedy or Claire Redfield, enters the locker room from the opposite side (LS). However, instead of the doorway on the back wall, the same space is occupied by a proportionally sized locker with a door hanging from its bottom hinge. Where Stephen would have stood in the film, an injured police officer now sits. This time, running vertically along the left edge of the screen frame, there is a beige coloured upturned wooden table, and once again to the left, cardboard boxes.

This replication of refashioned décor repeats itself again as Stephen enters the main office in extreme long shot (ELS). He enters from the locker room to appear in the office from screen-right. It is a relatively small room, bustling with many of the objects of décor. A busy notice board hangs on the wall. A wall mounted lamp shines just overhead. Desks are cluttered with an assortment of personal and office items; an ashtray, a picture frame, an ink blotter, in-trays, a telephone. Around the walls are filing cabinets, display cases, bookshelves, and tele-printer. A dead police officer sits slumped in front of an old radio unit. Again we can identify and compare this scene with the office in Mikami's RPD headquarters like for like. Here, the office is not linked directly to the locker room. Instead, it can be found on the first floor of the police station. This office is arranged in a slightly different fashion but one can still identify the obvious similarities. A busy notice board hangs on the wall. A wall mounted lamp shines just to the left. Desks are cluttered with an assortment of personal and office items; mugs and beakers, sweets and CDs, a computer. Around the walls are filing cabinets, display cases, bookshelves, and a fax machine. The dead police officer's corpse has gone (now the injured officer in the locker room) but in the same space a considerably more sophisticated radio system is now visible.

Again, referring to the film, Stephen rummages amongst the clutter for useful items (LS). In the foreground and still slumped at his desk, the dead police officer now sits in profile (medium long shot/ MLS). The lamp, brightly illuminated, shines just left of his head. In the RPD headquarters the player is presented with a similar view of the office. However, the desk and an empty chair now sit on the right of the screen and the ceiling lights mirror the angle of the dead police officer's desk lamp.

There are just too many similarities running through this particular sequence for it to be simply a matter of coincidence. The stylistic remediation of décor design can be found replicated in many other rooms throughout the RPD headquarters. However, the remediation of Romero's aesthetic is not solely confined to the composition of the police offices. There are numerous other remediations of location that appear throughout the Resident Evil RPGs, including the replication and refashioning of stairwells, tunnels and corridors, basements, machine rooms and exteriors.

From the evidence thus far, one can clearly follow the remediation of Romero's aesthetic into the Resident Evil RPG. Charting the remedial process back into Snyder's 2004 remake is a little more problematic, given that the initial screenplay has been drastically re-written with the visual narrative appearing significantly different from that of the original. Nonetheless, it is possible to demonstrate the process of remediation here also as it moves, reshaping and redefining the aesthetic from the original film, through the RPG and into the remake.

This time the location in question is the "the gun shop." In the original Romero film, the gun shop is located within Monroeville Mall and is accessed from the roof via an air conditioning duct. There is no resident owner. As location, it is merely a resource which is later stripped of its assets when the plot demands. When the interior of the shop is first viewed, it is from a high angle shot (LS) toward the left corner. It is well stocked with a substantial range of guns arranged in groups along the shop's walls. In front of the guns sits a glass counter that runs around the length of the walls with a small gap in the corner for access. Above the counter are a series of distinct large white letters interspersed with the mounted heads of stuffed animals. In Resident Evil 2, the gun shop reappears, remediated as "Kendo's Gun Shop", but now a stand-alone building. Unlike the film's gun shop, this one has a resident owner, Mr. Kendo, who has remained inside for protection. 
Outside the shop, the frontage is worn and weathered with a distinctly grubby urban feel. To the right of the door there are numerous posters randomly pasted to the wall. On entry, the player's choice of avatar is met by the owner. A cut scene interrupts to relay narrative information via a series of over-the-shoulder and shot-reverse-shots. The cut scene ends. Once again the remediation of décor is a direct refashioning inspired by the Romero aesthetic. Viewed from a similarly high angle, the shop has been modelled to look almost identical in layout to Romero's, with similar glass counters and overhead advertising signage.

To this point, I have demonstrated the remediation of the gun shop aesthetic from Romero's film and then refashioned into the Resident Evil where it now forms an integral part of the narrative and interactive game play. However, one can further chart the remedial process as the reworked gun shop aesthetic next moves from Resident Evil to appear in its replicated form in Snyder's film. Just like the game, the setting for the shop has left the mall and now stands alone as "Andy's Gun Works". From the outside, the building bears several remarkable resemblances to that of Mr. Kendo's. The frontage of "Andy's Gun Works" is heavily banded with similar linear decoration as is the design of the architectural structure. Furthermore, it possesses an even greater quality of the grubby urbanization and decay that shrouds Mr. Kendo's shop. Inside too, it bears a similar resemblance to the gun shop in the original film but with a more contemporaneous yet threatening and chaotic arrangement. It stocks much the same items and twice as many again.

In terms of design and layout, it would probably be true to suggest that all gun shops generally look similar to each other. But the aspect of the remedial process that is striking here lies not with the refashioning of the location but rather with the function of the setting by the reworked narrative. In the Resident Evil 2 RPG, Mr. Kendo's shop provides the illusion of a safe haven. With the sheer amount of weaponry at hand, survival must be a sure-fast certainty. However, following the cut scene in Resident Evil 2, the large shop windows are smashed and zombies pour through, overwhelm Mr. Kendo and then proceed to devour him. The player's choice of avatar must fend off the still hungry zombies as they begin to move toward and behind the glass counters toward their prey. Once the player's avatar has killed the zombies, he or she is then permitted to proceed forward from this location with newly acquired supplies, and into the next area of game play. This entrance by the zombies into Kendo's shop is a further direct refashioning of the events in the Mall shop. Once the bikers invade the mall, a short sequence soon follows that show Romero's zombies moving in exactly the same fashion and direction within the gun shop.

In Snyder's film, the remediation of the gun shop is quite different. It has very little in common with the shop in the original film other than in terms of aesthetic look and as a place to secure weaponry. However, it does have much more in common with the gun shop in Resident Evil 2. In a process of reverse remediation, it has borrowed from Resident Evil 2's reworked décor and then further refashioned it to suit its own requirements as setting, now integral to the narrative function of the heavily reworked storyline. Like Mr. Kendo's shop, it too has an owner - Andy. Like Mr. Kendo, Andy too has sought sanctuary within the shop but has found the need to barricade himself inside to survive. However, the object now is to rescue a self-imprisoned Andy rather than to secure weaponry. But once his character's function becomes superfluous to the narrative, he too is killed by invading zombies. The shifting function of the gun shop and the remediation of décor serve to demonstrate, as Bolter \& Grusin suggest, that remedial refashioning is in fact an ongoing dynamic process continually reshaping and redefining aesthetics.

I have now demonstrated the process of remediation operating in two distinct ways. In the first instance, I have demonstrated the process as a remediation of aesthetics between an original text - Romero's film, and a newer re-envisioning text - the Resident Evil 2 RPG; from an old media, the cinema, to a new media, the video game. In the second, I have demonstrated the process as it operates in reverse, to reclaim the refashioned aesthetic, in this case the remediation of décor from the Resident Evil 2 RPG, which is then reintegrated back into the cinematic form. However, Snyder's remake didn't simply reclaim refashioned elements of the décor. It incorporated new and original aesthetic characteristics and stylizations directly from the Resident Evil franchise and reworked them back into its own narrative and aesthetic structure.

Unlike the original film, the remake incorporates a more ludologically sympathetic narrative and introduces a range of additional locations into the plot. In doing so it remediates elements of sophisticated iconography that permeate Mikami's refashioned aesthetic. The "Police Dock" is replaced by a modern hospital bustling with technology. The mall, rather than being an uninhabited space, is now home to three security guards, 
surrounded by an array of large wall-mounted television screens that broadcast the latest up-to-the-minute satellite news. But perhaps the most telling aspect of remediation from the Resident Evil RPGs is the mode of escape employed by the surviving characters.

In the original film, the two survivors escape by helicopter. However, in the RPGs, escape involves two stages. The first involves getting to the means of escape without getting killed. In the case of Resident Evil it is to a helicopter. In Resident Evil 2, it is to a monster-sized train. Even then, escape is not guaranteed, as access to or use of each mode of transport is either hindered or blocked. Once problems are overcome, actual escape is achieved. This characteristic "spectacular getaway" of the RPG is remediated to prominently feature in Snyder's film. From a cast of entirely new characters, somewhat similar to the choice of avatars in both the Resident Evil Outbreak RPGs, a small group of survivors escape the mall in two heavily modified buses. The interior of the buses now become the setting for the next eight minutes, as they make their way toward their final means of escape. In both Resident Evil and Resident Evil 2, this journey takes around five to six minutes. It is obvious that the element of spectacle engendered by such sequences was borrowed from the RPGs to boost the film's appeal in much the same way as Mikami borrowed from the original aesthetic to shape his vision.

In addition to the refashioning of the wider aspects of décor, setting and elements contained therein, two other fundamental components of mise-en-scène which have also been extensively remediated within the Resident Evil RPGs are those of colour and lighting. Both play a significant role in the performance of the game play in addition to contributing to the wider aesthetic composition of the avatar's world. Likewise, the Snyder remake features a substantial shift in the use of both when compared to the Romero original. Previously I demonstrated how the remedial process could be traced from Romero's "Police Dock" to the RPD headquarters in Resident Evil 2. In much the same way, similar analysis can also be applied in terms of the remediation of colour and lighting.

In Romero's original film, he has applied a considered limited palette of blue and brown hues. The walls and ceilings are a plain pale blue, and the floor, a chequerboard pattern, is tiled in two shades of brown. The furniture within the office is of a grey-blue hue. In Mikami's refashioned police station, the colours are completely reversed. The same limited palette applies but the walls and furniture are now beige, and the chequerboard floor-tiles, shades of a similar blue hue. The use of lighting and shadow in each office is also similar. Both settings, film and game, are lit from a high downward angled key-light source, resulting in shadowing in the ceiling areas. The lighting appears diffuse, but in Romero's film the effect is to make the office appear cold and foreboding. In Mikami's remediation, the effect makes the office appear warm and inviting. The limited palette that permeates Romero's film creates at times a menacing and oppressive atmosphere.

Although there are moments of high contrast colour such as in the television studios, shopping mall department store, or whenever gore is present, much of the film's texture is subdued by the limitations imposed by the palette. Atmosphere is both heavy and suffocating indoors on account of the limited or diffuse use of overhead light sources. Exterior shots appear washed and anaemic, enhancing the authenticity of the blue-faced cadavers.

Throughout much of Mikami's refashioning, he too has chosen to apply a similar use of colour and lighting techniques to replicate the feel of the Romeroesque atmosphere. A similar limited palette consisting of hues of blue, browns and olive-greens are reserved for the distinctly gothic settings in the Resident Evil RPG such as the mansion corridors and rooms, or the underground sewer systems. Lighting in these settings is equally soft and diffuse, much less harsh than the Romero aesthetic and as a consequence, can be much more immersive from the player's point of view. Lighting again comes from overhead sources. Mikami's use of limited colour palettes also extends itself to highly stylized expressive use, particularly during animated cut-scenes, where strict aesthetic control is exercised, delineating one sequence or shot from the next.

This is a refashioning of the Romero aesthetic: a remedial extension to the established generic convention, and one which both validates and complements Mikami's inclusion of the iconography of science fiction. In comparison to Romero's film, the Snyder remake has done away with all the original characters except for the zombies themselves. Along with a complete rewrite and a radically reconstructed plotline a whole new assortment of characters make an appearance. In Romero's film, zombies appear blue faced as a result of a 
heavy application of expressive make-up by Tom Savini.

There are no rotting bits of flesh hanging from cadavers, neither are they splashed with the deep reds and browns associated with blood splatter. Rather, within the scope of the limited palette they appear in the main as clean faced and somewhat cartoon-like. Their menacing appearance, rather than by the use of make-up, is created by the use of shadow, partly due to lack of lighting facilities but in a controlled manner, by the use of a singular key light source either at eye-level or from a high vantage point. Mikami adopts Romero's model and again refashions it for the Resident Evil RPGs.

Much of the appearance of the zombies in the games directly correspond with those of the film, cream shirt with blue, black or brown trousers, with the addition of some in striking blue police shirts and dark blue trousers. However, during the RPG cut scenes, zombies are treated to a more realistic application of colour. They are portrayed, again in similar dramatic shadowing, splattered in the reds and browns of blood, gore and dirt and consequently command a more credible screen presence than those of Romero. The theatrical all-over even blue-toned faces have gone, to be replaced by much more convincing shades of browns and greys, more in keeping with the image of a rotting cadaver.

Snyder's film not only borrows from this refashioning but also places his cadavers in the vibrancy of daylight, enhancing both the texture and depth of tone and colour. Furthermore, in borrowing from the Resident Evil RPGs, Snyder places zombies in settings that weren't available to Romero in his original film. In one particular sequence, Snyder's characters have to pass through a dimly lit sewer system in order to reach Andy trapped in the gun shop. In the Resident Evil RPGs, the dimly lit sewer or tunnel features as a specific level in the majority of the games. Snyder capitalizes on this setting in his film. In the RPGs, zombies rise up from the water to attack the player's avatar. In the film, they first drop through a drainage cover overhead, fall into the water and become submerged before rising in much the same fashion as in the games. In the RPGs the colouring of the tunnels is a suggestive mix of dark greens and browns lit in semi-darkness to aid game play. In Snyder's film, these same tunnels are now shrouded in darkness with limited lighting and only the use of a direct face-on light source to highlight the menace posed by the advancing zombies. In another scene, shot outdoors in bright daylight, a blood-drenched and gaunt-looking zombie strikingly contrasts with the vibrancy of the greens and blues of the background in the full of summer. Again, lighting is used to accentuate the menace of this zombie. Although he is flooded from behind by the full vibrancy of natural sunlight, an additional strong light source is placed directly above and creates a striking effect of extensive and somewhat disturbing shadowing to the face. This particular zombie appears to be a refashioned response to cadavers from the RPGs who appear devoid of skin, revealing the entirety of their muscle structure.

This difference between the two films is quite striking. As Russell notes, "the remake of Dawn of the Dead was forced into production without Romero's artistic blessing" (Russell, 183) and deliberately followed in the wake of the success afforded to the Resident Evil RPGs and later screen forays, Boyle's 28 Days Later (2002), and Wright's Shaun of the Dead. In a profit driven industry, it is probable that Universal Picture's motivation to put the film into production would have been be financially premised rather than aesthetically altruistic (Ibid, 183). However their PR machine stated otherwise, as Russell notes:

This is a re-envisioning of a classic. There was not, is not, a valid reason to "remake" Dawn of the Dead. That's not what we set out to do, not what any of us wanted... We really saw this as a chance to continue the zombie genre for a new audience. (Ibid, 184)

Whatever the reasoning, in terms of Bolter \& Grusin's definition of the remedial process, it is clear that there is a refashioning of the aesthetic from Romero's Dawn of the Dead directly into and throughout the Resident Evil RPGs. A clear process of remediation occurs across all three texts. Furthermore, as I have also demonstrated, the direction of this process is fluid. Whether the now popularized benchmark aesthetic will restrict the generic development to particular franchise models is still open to question. It is too early to say.

However, if this indeed turns out to be the case, it need not be viewed as a negative development. If the foundational premise and aesthetic composition of each new franchise follows in the footsteps of the considered evolution of the aesthetic treatments afforded to the works of Romero, Mikami and Snyder, then the zombie's on-screen exploits should continue to enjoy commercial and popular success for some time to 
come: one merely recalls the longevity of the Star Trek series, some forty years thus far. Alternatively, even if fresh franchise models emerge, the benchmark standard has been elevated to such a level that audience expectations would not stand for anything less. The developing Silent Hill series proves this assertion to be true. Consequently, any new crop of generic offerings will almost certainly be of a sufficient calibre at every level of production to assure the zombie continued longevity. Whatever the next step in the generic evolution might be, the zombie has emerged as one of the twenty-first century's foremost iconic screen monsters.

\section{References}

Black, A. Zombies: Films that Call the Dead to Rise. Self published by A. G. Black, 1992.

Bolter, D. J. and R. Grusin. Remediation: Understanding New Media. Massachusetts: MIT Press, 2000.

Burn, A. and D. Carr. ?Defining Game Genres,? in Buckingham, D. D. Carr, et al. Computer Games: Text, Narrative and Play. Cambridge: Polity Press, 2006.

Dendle, P. The Zombie Movie Encyclopedia. London: McFarland, 2000.

Gelder, K. (ed.) The Horror Reader. Abingdon: Routledge, 2005.

Hood, R., Nights of the Celluloid Dead: A History of the Zombie Film (2002). http://www.phillyburbs.com/zombies/essay/on

Jancovich, M. Horror. London: B. T. Batsford Ltd, 1992.

King, G. and T. Krzywinska (eds.). Screenplay: Cinema, Viedogames, Interfaces. London: Wallflower Press, 2002.

Poole, S. Trigger Happy: The Inner Life of Video Games. London: Fourth Estate, 2000.

Russell, J. Book of the Dead: The Complete History of Zombie Cinema. Godalming: Fab Press, 2005.

Wolf, M. J. P. and B. Perron (eds.). The Video Game Theory Reader. London. Routledge, 2003.

\section{Author Information}

Kevin STEWART is a postgraduate student at Film and Media Studies, University of Stirling, UK. His interests include the visual arts and aesthetics, in particular, for the cinema. His area of research encompasses the interface between video games and the cinema with respect to adaptation, aesthetics, narrative and spectatorship, focusing primarily on the horror, science-fiction and fantasy genres. 